\title{
Effect of intraoperative infusion of ketamine on remifentanil-induced hyperalgesia
}

\author{
Eunji Choi, Heeseung Lee, Hahck Soo Park, Guie Yong Lee, Youn Jin Kim, \\ and Hee-Jung Baik \\ Department of Anesthesiology and Pain Medicine, Ewha Womans University School of Medicine, Seoul, Korea
}

Background: Opioid induced hyperalgesia $(\mathrm{OIH})$ is related with high opioid dosage, a long duration of opioid administration, and abrupt discontinuation of infused opioids in anesthetic settings. Ketamine is known to attenuate OIH efficiently, but methods of administration and methods to quantify and assess a decrease in OIH vary. We demonstrated the existence of remifentanil-induced hyperalgesia and investigated the ability of ketamine to attenuate OIH.

Methods: Seventy-five patients undergoing laparoscopic gynecologic surgery under remifentanil-based anesthesia were assigned to one of the following groups: (1) group RL (remifentanil $0.05 \mu \mathrm{g} / \mathrm{kg} / \mathrm{min}$ ), (2) group RH (remifentanil $0.3 \mu \mathrm{g} /$ $\mathrm{kg} / \mathrm{min}$ ), or (3) group KRH (remifentanil $0.3 \mu \mathrm{g} / \mathrm{kg} / \mathrm{min}+$ ketamine $0.5 \mathrm{mg} / \mathrm{kg}$ bolus with $5 \mu \mathrm{g} / \mathrm{kg} / \mathrm{min}$ infusion intraoperatively). Desflurane was administered for maintenance of anesthesia to target bispectral index scores (40-60) and hemodynamic parameters (heart rate and blood pressure $< \pm 20 \%$ of baseline values). All parameters related to OIH and its attenuation induced by ketamine were investigated.

Results: There was no significant difference among the three groups related to demographic and anesthetic parameters except the end-tidal concentration of desflurane. Additional analgesic consumption, numerical rating scale scores at 6 and $24 \mathrm{~h}$, and cumulative fentanyl dose were significantly higher in group RH than in the other two groups. The value difference of the Touch-Test sensory evaluation was significantly higher negative in group RH than in the other two groups.

Conclusions: Remifentanil-induced hyperalgesia is significantly attenuated by intraoperative bolus and infusion of ketamine. Ketamine also decreased tactile sensitization, as measured by Touch-Test sensory evaluation.

Key Words: Central sensitization, Hyperalgesia, Ketamine, Remifentanil.

Corresponding author: Heeseung Lee, M.D., Ph.D.

Department of Anesthesiology and Pain Medicine, Ewha Womans University School of Medicine, 1071, Anyangcheon-ro, Yangcheongu, Seoul 07985, Korea

Tel: 82-2-2650-2670, Fax: 82-2-2655-2924

E-mail: leehee@ewha.ac.kr

Received: April 16, 2015.

Revised: 1st, May 20, 2015; 2nd, June 8, 2015.

Accepted: June 8, 2015.

Korean J Anesthesiol 2015 October 68(5): 476-480

http://dx.doi.org/10.4097/kjae.2015.68.5.476

\section{Introduction}

Opioids are a prerequisite for perioperative analgesia in the anesthetic setting, but can be a double-edged sword due to the side effect of opioid-induced hyperalgesia (OIH). OIH is related to high opioid dosage, long duration of opioid use, and abrupt discontinuation of opioids after surgery. Therefore, many mechanism-based combinations of other adjuvant drugs have been used to attenuate sensitization of the central pronociceptive process and reduce the unpleasant hyperalgesic response [1].

Ketamine, an N-methyl-D-aspartate (NMDA) antagonist, efficiently decreases the hyperalgesic response induced by opioids. Ketamine modulates the pronociceptive sensitization process

(c) This is an open-access article distributed under the terms of the Creative Commons Attribution Non-Commercial License (http://creativecommons.org/ licenses/by-nc/4.0/), which permits unrestricted non-commercial use, distribution, and reproduction in any medium, provided the original work is properly cited. 
and attenuates postoperative hyperalgesic responses. Multiple modes of administration have been used to evaluate the effects of ketamine on postoperative hyperalgesic response, including a single bolus, a bolus plus an intraoperative intravenous infusion, and an intraoperative infusion plus a consecutive postoperative infusion [2]. Reduction of postoperative hyperalgesia can be evaluated by decrease in pain scores, a delay of time to the first request for analgesic drugs, a decrease in total opioid consumption, and a decrease in additional analgesics. Rarely, a postoperative hyperalgesic response was the primary endpoint [3-5] for evaluation of the hyperalgesic effect of ketamine. In this study we tried to make a point of confirming the antihyperalgesic ability of ketamine in a view point of not only reduction of opioid consumption but also increase of tactile sensitivity by TouchTest sensory evaluator.

We attempted to demonstrate the antihyperalgesic effect of ketamine on high-dose remifentanil-based anesthesia. Ketamine was administrated as an intravenous bolus and as a subsequent intraoperative infusion. In addition, the Touch-Test sensory threshold was used to evaluate the periumbilical area to detect changes in tactile sensitization and hyperalgesic response, instead of the Von Frey monofilament.

\section{Materials and Methods}

We enrolled seventy five patients ( $\mathrm{n}=25$ per group) scheduled for elective laparoscopic gynecological surgery. All patients were 23 to 60 years old, American Society of Anesthesiologists physical status I or II. Patients were excluded from the study when they had previous history of sedative and opioid medications, alcohol abuse, or significant medical or psychiatric conditions. When patients visited the preoperative anesthetic clinic, they were taught how to handle the numerical rating scale (NRS) score, the patient-controlled analgesia (PCA) device, and the Touch-Test sensory evaluation [6]. After obtaining Institutional Review Board approval [No: 2014-10-044-002] and written informed consent, patients were randomly divided into three groups on the day of surgery. Postoperative fentanyl consumption was used to calculate the statistical power. A sample size estimate indicated that 24 patients per group would give a power of $80 \%$ at a a level of 0.05 for detecting a difference in fentanyl consumption of at least $30 \%$. All patients were noninvasively monitored to collect data on blood pressure (BP), oxygen saturation $\left(\mathrm{SpO}_{2}\right)$ with pulse oximetry, electrocardiogram, end-tidal concentration of desflurane and $\mathrm{CO}_{2}$, bispectral index (BIS) and esophageal temperature. Total fluid infusion and urine output were also monitored and recorded during anesthesia. Induction of anesthesia was conducted with an intravenous bolus dose of remifentanil $(0.5 \mu \mathrm{g} / \mathrm{kg})$, followed by propofol $(1.5 \mathrm{mg} / \mathrm{kg})$, glycopyrrolate $(0.2 \mathrm{mg})$, and midazolam $(0.05 \mathrm{mg} / \mathrm{kg})$. Endotra- cheal intubation was conducted after rocuronium $(0.6 \mathrm{mg} / \mathrm{kg})$ in all groups. All patients were assigned into three groups: group $\mathrm{RL}$ received $0.05 \mu \mathrm{g} / \mathrm{kg} / \mathrm{min}$ remifentanil; group $\mathrm{RH}$ received $0.3 \mu \mathrm{g} / \mathrm{kg} / \mathrm{min}$ remifentanil; and group $\mathrm{KRH}$ received $5 \mu \mathrm{g} / \mathrm{kg} /$ min ketamine and $0.3 \mu \mathrm{g} / \mathrm{kg} / \mathrm{min}$ remifentanil during maintenance. Group KRH only received an intravenous bolus dose of ketamine $(0.5 \mathrm{mg} / \mathrm{kg})$ during induction. The infusion rates of ketamine and remifentanil did not change during anesthetic maintenance. The end-tidal concentration of desflurane (volume $\%)$ of desflurane mixed with oxygen $\left(\mathrm{O}_{2} 50 \%\right)$ was recorded and changed according to the target BIS (40 to 60) and acceptable blood pressure and heart rate $( \pm 20 \%$ of baseline). Ephedrine (5 mg) or glycopyrrolate $(0.2 \mathrm{mg})$ was administered when a patient's hemodynamic parameters left the acceptable range. Infusion of ketamine and remifentanil was discontinued at the final surgical suture. When BIS reached 90 and hand grip (5 s) was possible, extubation was performed. The time to extubation (min) was measured from discontinuation of the study drug infusion to extubation. An intravenous bolus of ramosetron (0.3 $\mathrm{mg}$ ) was administered after the final stitch and another bolus of ramosetron $(0.3 \mathrm{mg})$ was mixed with the PCA pump, which contained $800 \mu \mathrm{g}$ fentanyl in a total volume of $60 \mathrm{ml}$ of saline and was connected to each patient. This PCA device was set at a basal infusion of $0.5 \mathrm{ml} / \mathrm{hr}$, with a bolus dose of $0.5 \mathrm{ml}$ with 15 min lockout interval. Postoperative pain intensity was measured by verbal NRS score at $0 \mathrm{~h}$ (immediately after surgery) and then after 1,6 , and $24 \mathrm{~h}$ after surgery by an investigator who was blinded to the patients' group (NRS0, NRS1, NRS6, NRS24, respectively). Time ( $\mathrm{min}$ ) to first analgesic, which was ketorolac, and total additional analgesic dose $(\mathrm{mg})$ were also recorded. If the pain scores by NRS of the patient were over 4, $30 \mathrm{mg}$ ketorolac was administered and if the pain scores by NRS were still over 4 again, another consecutive $15 \mathrm{mg}$ of ketorolac was added repeatedly during the patient's stay in the postanesthetic care unit (PACU).

The Touch-Test sensory threshold was measured preoperatively and $24 \mathrm{~h}$ after surgery using a Semmes-Weinstein monofilament (SWMF, North Coast Medical, Inc., San Jose, CA, USA) 20 piece full kit (NC12775), with an evaluator size of 1.65-6.65 and a target force of $0.008-300 \mathrm{~g}$. The Touch-Test sensory evaluator was applied on peri-incisional areas $2 \mathrm{~cm}$ above the perpendicular line of the optimal port site. The filament was pressed at a $90^{\circ}$ angle against the skin until it bowed and was held in place for $1.5 \mathrm{~s}$ and then removed. For monofilaments from 1.65 to 4.08 , the stimulus was applied in the same location up to 3 times to elicit a response. A single response indicated a positive response. For filaments 4.17 to 6.65 , the stimulus was applied one time only. The patient was instructed to respond by saying "yes" or "touch" when the stimulus was felt. The patient's vision was occluded by using a shield or by having the patient look 
away. If the patient did not respond to the stimulus, the process was repeated with the next largest monofilament. A diminished threshold of sensory evaluation compared with the preoperative baseline suggested desensitization of peripheral sensory perception. Side effects including hypotension, bradycardia, delirium, shivering, and postoperative nausea and vomiting (PONV) were recorded. Shivering and PONV were treated in the PACU with a warm air-blanket and additional intravenous ramosetron $(0.3$ $\mathrm{mg}$ ), respectively.

Comparisons of the following parameters among the three groups were performed by one-way ANOVA with Bonferroni post-hoc analysis using GraphPad Prism (Prism version 6.0, GraphPad Software, Inc., San Diego, CA, USA): age, body weight, baseline hemodynamics (blood pressure, heart rate), duration of anesthesia, input, output, the end-tidal concentration of desflurane (volume \%), time to extubation after surgery, time to first analgesic requirement, additional analgesic consumption during PACU stay, pain scores by NRS $(0,1,6$, and $24 \mathrm{~h}$ after surgery), Touch-Test sensory evaluation (preoperative, postoperative $24 \mathrm{~h}$, and differences), and cumulative fentanyl dose for $48 \mathrm{~h}$ after surgery. $\mathrm{P}<0.05$ was considered statistically significant

\section{Results}

No patient was dropped during the study. There were no significant differences among the three groups related to demographic and anesthetic parameters, such as age, body weight, baseline blood pressure (systolic, diastolic, mean), baseline heart rate, duration of anesthesia, input, output, or time to extubation after surgery. The mean end-tidal concentration of desflurane group RL was higher than other 2 groups $(\mathrm{P}<0.05$, Table 1$)$.

Table 1. Demographic and Anesthetic Data

\begin{tabular}{lccc}
\hline & $\begin{array}{c}\text { Group RL } \\
(\mathrm{n}=25)\end{array}$ & $\begin{array}{c}\text { Group RH } \\
(\mathrm{n}=25)\end{array}$ & $\begin{array}{c}\text { Group KRH } \\
(\mathrm{n}=25)\end{array}$ \\
\hline Age (yr) & $46.9 \pm 9.2$ & $43.7 \pm 7.6$ & $44.4 \pm 9.2$ \\
Weight (kg) & $56.8 \pm 7.2$ & $60.4 \pm 7.9$ & $58.6 \pm 8.5$ \\
Baseline Blood Pressure (mmHg) & & \\
$\quad$ Systolic & $117.7 \pm 12.6$ & $120.0 \pm 15.1$ & $116.9 \pm 14.0$ \\
$\quad$ Diastolic & $71.5 \pm 11.5$ & $70.7 \pm 11.0$ & $71.7 \pm 11.7$ \\
Mean & $86.8 \pm 10.6$ & $87.1 \pm 10.4$ & $86.4 \pm 10.9$ \\
Baseline Heart Rate (beats/min) & $76.9 \pm 13.2$ & $75.8 \pm 12.0$ & $77.4 \pm 11.2$ \\
Duration of Anesthesia (min) & $132.4 \pm 35.7$ & $139.8 \pm 50.0$ & $129.8 \pm 27.7$ \\
Mean end-tidal concentration of desflurane (volume \%) & $5.8 \pm 0.5 *$ & $3.4 \pm 0.5$ & $3.2 \pm 0.4$ \\
Time to extubation after surgery (min) & $4.0 \pm 2.4$ & $3.7 \pm 2.4$ & $3.0 \pm 2.4$ \\
\hline
\end{tabular}

All parameters are expressed as means \pm standard deviation (SD). Group RL: remifentanil ( $0.05 \mu \mathrm{g} / \mathrm{kg} / \mathrm{min})$, group RH: remifentanil $(0.3 \mu \mathrm{g} / \mathrm{kg} /$ $\min )$, and group $\mathrm{KRH}$ : ketamine and remifentanil $(0.3 \mu \mathrm{g} / \mathrm{kg} / \mathrm{min})$. There were no significant differences in demographic and anesthetic parameters between groups. *The mean end-tidal concentration of desflurane group RL was higher than other 2 groups $(\mathrm{P}<0.05)$.

Table 2. Parameters for Pain Intensity and Touch-Test Sensory Evaluation

\begin{tabular}{|c|c|c|c|}
\hline & $\begin{array}{l}\text { Group RL } \\
(\mathrm{n}=25)\end{array}$ & $\begin{array}{c}\text { Group RH } \\
(\mathrm{n}=25)\end{array}$ & $\begin{array}{c}\text { Group KRH } \\
\quad(\mathrm{n}=25)\end{array}$ \\
\hline Time to first analgesic requirement ( $\mathrm{min}$ ) & $52.1 \pm 27.0$ & $39.6 \pm 18.4$ & $51.6 \pm 26.7$ \\
\hline Additional analgesic consumption during PACU stay $(\mathrm{mg})$ & $9.6 \pm 14.3$ & $25.2 \pm 18.7^{*}$ & $16.8 \pm 21.4$ \\
\hline \multicolumn{4}{|l|}{ Pain scores by numerical rating scale (NRS) } \\
\hline $0 \mathrm{~h}$ after surgery & $4.0 \pm 1.2$ & $4.5 \pm 1.6$ & $4.2 \pm 1.1$ \\
\hline $1 \mathrm{~h}$ after surgery & $3.4 \pm 1.2$ & $3.8 \pm 1.0$ & $3.3 \pm 1.1$ \\
\hline $6 \mathrm{~h}$ after surgery & $2.2 \pm 1.1$ & $2.9 \pm 1.3^{\dagger}$ & $2.0 \pm 0.8$ \\
\hline $24 \mathrm{~h}$ after surgery & $1.2 \pm 0.5$ & $2.0 \pm 1.5^{\dagger}$ & $1.0 \pm 0.5$ \\
\hline \multicolumn{4}{|l|}{ Touch-Test sensory evaluation } \\
\hline Preoperative & $4.05 \pm 0.16$ & $4.01 \pm 0.46$ & $4.02 \pm 0.16$ \\
\hline Postoperative & $3.92 \pm 0.43$ & $3.30 \pm 0.78^{\dagger}$ & $3.76 \pm 0.64$ \\
\hline Difference & $-0.13 \pm 0.37$ & $-0.72 \pm 0.72^{\dagger}$ & $-0.27 \pm 0.67$ \\
\hline Cumulative fentanyl dose $(\mu \mathrm{g})$ for $48 \mathrm{~h}$ after surgery & $243.3 \pm 77.9$ & $310.3 \pm 53.9^{\dagger}$ & $225.1 \pm 38.1$ \\
\hline
\end{tabular}

All parameters are expressed as means \pm standard deviation (SD). Group RL: remifentanil ( $0.05 \mu \mathrm{g} / \mathrm{kg} / \mathrm{min})$, group RH: remifentanil (0.3 $\mu \mathrm{g} / \mathrm{kg} / \mathrm{min})$, and group KRH: ketamine and remifentanil $(0.3 \mu \mathrm{g} / \mathrm{kg} / \mathrm{min}) .{ }^{*} \mathrm{P}<0.05$ versus group $\mathrm{RL} .{ }^{\dagger} \mathrm{P}<0.05$ versus the other 2 groups. Difference of Touch-Test sensory evaluation is calculated the value between (postoperative - preoperative). 
Additional analgesic (ketorolac) consumption during the PACU stay was significantly higher in group $\mathrm{RH}$ than in group RL. Pain scores by NRS at 6 and 24 h after surgery were significantly higher in group $\mathrm{RH}$ than in the other two groups. The preoperative value of the Touch-Test sensory evaluation did not differ significantly between the three groups. The postoperative value of the Touch-Test sensory evaluation was significantly lower in group $\mathrm{RH}$ than in the other two groups. The value difference [postoperative - preoperative] was also significantly higher in group RH than in the other two groups, along with the cumulative fentanyl dose ( $\mu$ g) for $48 \mathrm{~h}$ after surgery (Table 2 ).

No additional intravenous ramosetron was needed for PONV. Two cases of shivering were detected in group $\mathrm{RH}$, but subsided after application of a warm air-blanket.

\section{Discussion}

Remifentanil, a commonly used perioperative ultrashortacting opioid analgesic, commonly induces postoperative hyperalgesia associated with high dosage, long duration of use, and acute withdrawal [7-10], though the specifics vary based on clinical experimental designs and settings [11-13]. Hyperalgesia is defined as "increased pain from a stimulus that normally provokes pain" [14]. Sensitization induced by opioids is initially characterized by "an increased nociceptive response to a drug that follows its repeated intermittent administration," known as "reverse opioid tolerance" [15]. Although sensitization and tolerance are opposite phenomena, they are expressed concomitantly at the same level of biological processes [16]. It is believed that pain modulation occurs during this biologic process, and a new set equilibrium can be established between nociception and antinociception. In this case, more hyperalgesia can be expected, but more sensitization and tolerance can also be developed. Group RH had significantly higher 6 and $24 \mathrm{~h}$ NRS scores and a higher $48 \mathrm{~h}$ fentanyl dose than group RL. Analgesic consumption in the PACU was also significantly higher in group $\mathrm{RH}$ than in group RL, indicating the development of remifentanilinduced hyperalgesia.

Proposed mechanisms of acute opioid tolerance include activation of NMDA antagonists [17], inactivation of mu ( $\mu$ ) opioid receptor peptide [18], and increased secretion of dynorphin and calcitonin-gene related peptide in the dorsal horn of the spinal cord [20]. Sensitization and concomitant development of acute tolerance can produce postoperative hyperalgesia. Therefore, hyperalgesia could be attenuated by administration of ketamine [20-22], which is an NMDA antagonist. Group RH showed a significantly higher pain score by NRS ( $24 \mathrm{~h}$ after surgery) and higher fentanyl consumption $(48 \mathrm{~h})$ than patients who received high dose remifentanil with a ketamine infusion (group KRH). The total fentanyl consumption ( $48 \mathrm{~h}$ ) in group $\mathrm{KRH}$ was signif- icantly reduced up to $32 \%$ compared to group $\mathrm{RH}$. A low-dose infusion of ketamine reduced opioid consumption up to $40 \%$ [2]. Reduction of pain scores and postoperative opioid consumption demonstrated that an intraoperative infusion of ketamine was clinically effective enough to attenuate the hyperalgesic response induced by high-dose remifentanil. Reduction of pain score by NRS among three groups was investigated at the independent time point $(0,1,6,24$ h respectively) by ANOVA not at the dependent serial time point by repeated measures of ANOVA. Therefore, the intergroup differences of pain score by NRS at the specific time point should be considered.

The Touch-Test sensory evaluator is indicated for diagnoses including nerve compression syndromes, peripheral neuropathy, thermal injuries, and postoperative nerve repair. Each TouchTest sensory evaluator is individually calibrated to deliver its targeted force within a 5\% standard deviation and provides a noninvasive evaluation of the cutaneous sensation threshold throughout the body with objective and repeatable results [6,23-26]. The Touch-Test sensory evaluation using SWMF can demonstrate changes in tactile sensitivity. If the postoperative value minus the preoperative value shows a higher negative number, that means that tactile sensitivity increased and that a hyperalgesic response may occur. The Touch-Test sensory evaluation is seldom used for acute postoperative conditions; it is more commonly used to evaluate neuroplasticity, central and peripheral desensitization of neuronal damage, and neuronal inflammation [23-26]. Group RH showed significantly higher negative SMWF numbers on the Touch-Test sensory evaluation than group KRH and group RL. This demonstrates that infusion of ketamine was clinically effective enough to attenuate tactile sensitivity and the hyperalgesic response induced by high dose remifentanil.

Lee et al. [5] showed antihyperalgesic effects of dexmedetomidine on high-dose remifentanil-induced hyperalgesia. This group used Von Frey filaments to evaluate mechanical hyperalgesia as the primary endpoint. We opted to use the Touch-Test sensory evaluation as it is less invasive and easier to conduct than the Von Frey filament test. Ketamine has fewer side effects than dexmedetomidine, especially hypotension, and has its intrinsic sympathomimetic activities in combination with high-dose remifentanil based anesthesia. Moreover, dexmedetomidine and ketamine have similar antihyperalgesic effects on high-dose remifentanil-induced hyperalgesia. Although dexmedetomidine creates less respiratory depression, the time to extubation ranged from 3.6 to $4.3 \mathrm{~min}$ in our subjects, which was shorter than the previously reported 13 to 16 min [5]. Ketamine also has an economic advantage over dexmedetomidine.

Taken together, high-dose remifentanil-induced hyperalgesia can be efficiently attenuated by an intraoperative infusion of ketamine. Ketamine also can decrease peripheral tactile sensitivity induced by high-dose remifentanil, based on Touch-Test 
sensory evaluation. To increase the quality of perioperative life in high-dose remifentanil based anesthesia, intraoperative ket- amine could be used safely to modulate hyperalgesic responses to opioids and increase patient satisfaction.

\section{References}

1. Lee HJ, Yeomans DC. Opioid induced hyperalgesia in anesthetic settings. Korean J Anesthesiol 2014; 67: 299-304.

2. Jouguelet-Lacoste J, La Colla L, Schilling D, Chelly JE. The use of intravenous infusion or single dose of low-dose ketamine for postoperative analgesia: a review of the current literature. Pain Med 2015; 16: 383-403.

3. Stubhaug A, Breivik H, Eide PK, Kreunen M, Foss A. Mapping of punctuate hyperalgesia around a surgical incision demonstrates that ketamine is a powerful suppressor of central sensitization to pain following surgery. Acta Anaesthesiol Scand 1997; 41: 1124-32.

4. De Kock M, Lavand'homme P, Waterloos H. 'Balanced analgesia' in the perioperative period: is there a place for ketamine? Pain 2001; 92: 373-80.

5. Lee C, Kim YD, Kim JN. Antihyperalgesic effects of dexmedetomidine on high-dose remifentanil-induced hyperalgesia. Korean J Anesthesiol 2013; 64: 301-7.

6. Fischer SG, Collins S, Boogaard S, Loer SA, Zuurmond WW, Perez RS. Intravenous magnesium for chronic complex regional pain syndrome type 1 (CRPS-1). Pain Med 2013; 14: 1388-99.

7. Vinik HR, Kissin I. Rapid development of tolerance to analgesia during remifentanil infusion in humans. Anesth Analg 1998; 86: 1307-11.

8. Guignard B, Bossard AE, Coste C, Sessler DI, Lebrault C, Alfonsi P, et al. Acute opioid tolerance: intraoperative remifentanil increases postoperative pain and morphine requirement. Anesthesiology 2000; 93: 409-17.

9. Crawford MW, Hickey C, Zaarour C, Howard A, Naser B. Development of acute opioid tolerance during infusion of remifentanil for pediatric scoliosis surgery. Anesth Analg 2006; 102: 1662-7.

10. Hood DD, Curry R, Eisenach JC. Intravenous remifentanil produces withdrawal hyperalgesia in volunteers with capsaicin-induced hyperalgesia. Anesth Analg 2003; 97: 810-5.

11. Gustorff B, Nahlik G, Hoerauf KH, Kress HG. The absence of acute tolerance during remifentanil infusion in volunteers. Anesth Analg 2002; 94: 1223-8.

12. Cortinez LI, Brandes V, Munos HR, Guerrero ME, Mur M. No clinical evidence of acute opioid tolerance after remifentanil-based anaesthesia. Br J Anaesth 2001; 87: 866-9.

13. Lee LH, Irwin MG, Lui SK. Intraoperative remifentanil infusion does not increase postoperative opioid consumption compared with $70 \%$ nitrous oxide. Anesthesiology 2005; 102: 398-402.

14. Lee H. Opioid-induced hyperalgesia. J Korean Med Assoc 2014; 57: 41-6.

15. Robinson TE, Becker JB. Enduring changes in brain and behavior produced by chronic amphetamine administration: a review and evaluation of animal models of amphetamine psychosis. Brain Res 1986; 396: 157-98.

16. Ali NM. Hyperalgesic response in a patient receiving high concentrations of spinal morphine. Anesthesiology 1986; 65: 449.

17. Kissin I, Bright CA, Bradley EL Jr. Acute tolerance to continuously infused alfentanil: the role of cholecystokinin and N-methyl-D-aspartatenitric oxide systems. Anesth Analg 2000; 91: 110-6.

18. Trafton JA, Abbadie C, Marek K, Basbaum AI. Postsynaptic signaling via the [mu]-opioid receptor: responses of dorsal horn neurons to exogenous opioids and noxious stimulation. J Neurosci 2000; 20: 8578-84.

19. Gardell LR, Wang R, Burgess SE, Ossipov MH, Vanderah TW, Malan TP Jr, et al. Sustained morphine exposure induces a spinal dynorphindependent enhancement of excitatory transmitter release from primary afferent fibers. J Neurosci 2002; 22: 6747-55.

20. Guignard B, Coste C, Costes H, Sessler DI, Lebrault C, Morris W, et al. Supplementing desflurane-remifentanil anesthesia with small-dose ketamine reduces perioperative opioid analgesic requirements. Anesth Analg 2002; 95: 103-8.

21. Ohnesorge H, Feng Z, Zitta K, Steinfath M, Albrecht M, Bein B. Influence of clonidine and ketamine on m-RNA expression in a model of opioid-induced hyperalgesia in mice. PLoS One 2013; 8: e79567.

22. Joly V, Richebe P, Guignard B, Fletcher D, Maurette P, Sessler DI, et al. Remifentanil-induced postoperative hyperalgesia and its prevention with small-dose ketamine. Anesthesiology 2005; 103: 147-55.

23. Kaluga E, Kostiukow A, Samborski W, Rostkowska E. Tactile sensitivity on the hands skin in rheumatic patients. Postepy Dermatol Alergol 2014; 31: 139-45.

24. Baraz S, Zarea K, Shahbazian HB, Latifi SM. Comparison of the accuracy of monofilament testing at various points of feet in peripheral diabetic neuropathy screening. J Diabetes Metab Disord 2014; 13: 19.

25. Feng Y, Schlösser FJ, Sumpio BE. The Semmes Weinstein monofilament examination as a screening tool for diabetic peripheral neuropathy. J Vasc Surg 2009; 50: 675-82.

26. Aherrera AS, Pincus DJ, Vernadakis AJ, Pandya SN. Evaluation of abdominal cutaneous sensibility following abdominoplasty. Plast Reconstr Surg 2015; 135: e526-32. 